\title{
Timing of harvesting reverses the effect of twice cutting with
}

\section{ratoon rice [version 1; peer review: 1 approved]}

\author{
Masato Oda(D1) Huynh Van Thao (iD)2, Chiem Nguyen Huu² \\ 1 Japan International Research center for Agricultural Sciences, Tsukuba, Japan \\ ${ }^{2}$ College of Environment and Natural resources, Can Tho University, Can Tho, Vietnam
}

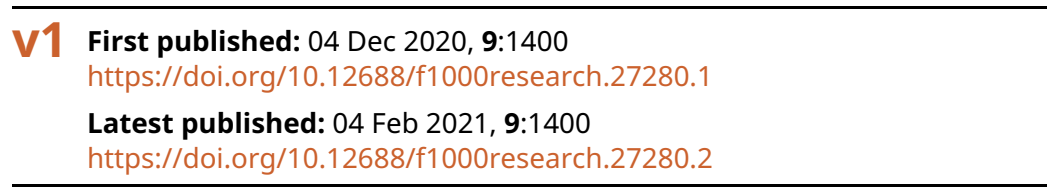

\section{Abstract}

A new ratoon rice cropping method known as the SALIBU system, which uses the lower nodes of the stubble, is gradually spreading throughout the tropical regions. In the technology package, 'cutting twice' has a large effect on the number of ratoons (tillers), and interestingly, the effect changed from positive to negative with changes in the management conditions used to cultivate rice. A previous study investigated conditions including fertilizing, water management, and growth stage at harvesting; however, which of these conditions has the greatest effect on the effect of 'cutting twice' remains unclear. We performed a pot experiment to clarify which of the level of fertilizer or the delay of harvesting time affects the number of ratoons. The results showed that with a short delay in harvesting there were almost no ratoons, a long delay in harvesting resulted in many ratoons. By contrast, the single cutting results in ratoons. This indicates the negative effect of cutting twice occur due to earlier harvesting. However, adding fertilizer results in more ratoons, and the response to delayed harvesting showed a similar tendency; in short, no reverse effect occurred due to the level of fertilizer. Harvesting earlier (at the physiological maturation stage; $25 \%$ green husk) than normal is emphasized in the SALIBU technology package. However, our results show the 'cutting twice' has a negative effect on the number of ratoons when harvesting early.

\section{Keywords}

Mekong Delta, ratoon rice cropping, SALIBU, triple cropping rice, Harvesting timing.

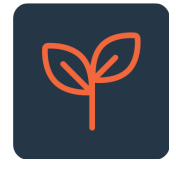

This article is included in the Agriculture, Food and Nutrition gateway.

\section{Open Peer Review \\ Approval Status $\vee$ \\ 12 \\ version 2 \\ (revision)

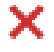 \\ 04 Feb 2021 \\ version 1 \\ 04 Dec 2020

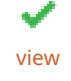 \\ 1. Syarifa Mayly iD, Al Washliyah Medan \\ University, Medan, Indonesia \\ 2. Chenfei Dong, Jiangsu Vocational College of Agriculture and Forest, Zhenjiang, China Any reports and responses or comments on the article can be found at the end of the article.}


Corresponding author: Masato Oda (oda.masato@affrc.go.jp)

Author roles: Oda M: Conceptualization, Data Curation, Formal Analysis, Investigation, Methodology, Writing - Original Draft Preparation; Van Thao H: Conceptualization, Data Curation, Formal Analysis, Investigation, Methodology, Writing - Original Draft Preparation; Nguyen Huu C: Conceptualization, Formal Analysis, Methodology, Writing - Review \& Editing

Competing interests: No competing interests were disclosed.

Grant information: The author(s) declared that no grants were involved in supporting this work.

Copyright: ( 2020 Oda $\mathrm{M}$ et al. This is an open access article distributed under the terms of the Creative Commons Attribution License, which permits unrestricted use, distribution, and reproduction in any medium, provided the original work is properly cited.

How to cite this article: Oda $\mathrm{M}$, Van Thao $\mathrm{H}$ and Nguyen Huu C. Timing of harvesting reverses the effect of twice cutting with ratoon rice [version 1; peer review: 1 approved] F1000Research 2020, 9:1400 https://doi.org/10.12688/f1000research.27280.1

First published: 04 Dec 2020, 9:1400 https://doi.org/10.12688/f1000research.27280.1 


\section{Introduction}

The cultivation of rice using ratooning has several advantages over conventional cultivation, including lower costs, lower labor intensity, and lower greenhouse gas emissions (Sacks, 2013; Safruddin, 2017). A new practice for ratooning rice crops using the lower nodes of rice stubble, known as the SALIBU system, is gradually spreading throughout the tropical regions (Fitri et al., 2019; Yamaoka et al., 2017). The practice involves harvesting most of the above-ground portion of the plant but leaves the growing shoots intact. The SALIBU method implements 10 additional management practices to conventional management of rice cultivation in Indonesia. (1) early harvesting, (2) pre-fertilization (at seven days before harvesting), (3) cutting twice (rice was harvested $25 \mathrm{~cm}$ above the ground, then cut again at $3-5 \mathrm{~cm}$ above ground), (4) late irrigation (irrigation was started on day 14 after harvesting), (5) hand weeding, (6) dividing (dividing hills into two or three tillers and replanting to fill the space), (7) pushing (pushing the rice plants into the soil if the root came up on the soil surface), (8) removing excess plants (to keep original plant density), (9) draining from day 29 to 43 after harvesting, and (10) draining for the above (5) to (9) treatments. However, this new methodology has yet to be well studied. Oda et al. (2019) evaluated the Cohens' $d$ effect size (Cohen, 1992) of each practice in the technology package and clarified that the process of cutting twice has a large effect. Interestingly, the effect can be reversed depending on the management conditions. There is a large positive effect when poor management conditions are used but a medium negative effect when standard management conditions of direct seeding triple-cropping rice in the Mekong Delta are employed. The poor management conditions consisted of not using fertilizer, continuous-flooding water management, and late harvesting. There an interaction between the management conditions and the practice of cutting twice; however, which of the three conditions was responsible for the interaction has not been clarified. We assumed that it was late harvesting. Therefore, we examined the relationship between delayed harvesting and the number of ratoons under conditions with and without fertilizer. The results showed that the interaction does arise from the delay in harvesting.

\section{Methods}

A relationship between delayed harvesting and the number of ratoons was analyzed. We harvested rice plants grown under conditions of both with and without fertilizer. Rice was harvested on the day when $75 \%$ of the seeds on the main stems turned yellow (days 0 ), and after on days 4,8 , and 14 . The water management approach we adopted was alternative wet and dry (AWD). Note, SALIBU practices are not used in this experiment.

\section{Treatments}

The experiment was conducted in a screen-house at Can Tho University, Can Tho city, Vietnam from October 2019 to February 2020. The climate is classified as tropical savanna (Aw) and the range of the day average temperature of October to February is 26.0 to $27.3^{\circ} \mathrm{C}$ (Climate-data.org). Containers of size $38 \times 58 \times 30 \mathrm{~cm}(1 \times \mathrm{w} \times \mathrm{h})$ were filled with silty clay soil (52\% clay, $48 \%$ silt, $<1 \%$ sand, originally collected from a farmer's paddy filed in the Mekong Delta; $10^{\circ} 22^{\prime} \mathrm{N}, 105^{\circ} 58^{\prime} \mathrm{E}$ ) to a depth of $20 \mathrm{~cm}$. To remove excess nutrients, the soil was watered, stirred, and the supernatant water was removed. This procedure was conducted three times. Rice (Oryza sativa) seeds of variety ST24 (105 - 110 days provided by Can Tho University) were planted, two seeds per hill, with nine hills per pot (in a $3 \times 3$ arrangement). The application of fertilizer followed the standards used for direct seeding of triple-cropping rice in the Mekong Delta (AN Giang's DARD, 2014; on day seven (27.6 kg ha-1 $\mathrm{N}, 45.2 \mathrm{~kg} \mathrm{ha}^{-1} \mathrm{P}_{2} \mathrm{O}_{5}, 3.68 \mathrm{~kg} \mathrm{ha}^{-1} \mathrm{~K}_{2} \mathrm{O}$ ), $20\left(36.7 \mathrm{~kg} \mathrm{ha}^{-1} \mathrm{~N}\right)$, and $42\left(27.6 \mathrm{~kg} \mathrm{ha}^{-1} \mathrm{~N}, 3.68 \mathrm{~kg} \mathrm{ha}^{-1} \mathrm{~K}_{2} \mathrm{O}\right)$ after seeding), or pots were left unfertilized. The water management approach used was alternative wetting and drying (AWD) between +3 and $-10 \mathrm{~cm}$ manually. Irrigation was initiated on day 7 after planting and the pots were drained 10 days before harvesting. Rice was harvested on the day when $75 \%$ of the seeds on the main stems turned yellow (as used with the SALIBU method (Yamaoka et al., 2017); days 0), and after on days 4, 8, and 14. Rice was first harvested at $25 \mathrm{~cm}$ aboveground, then cut again at approximately $5 \mathrm{~cm}$ aboveground on day 7 after each harvesting. The harvested rice straw was cut into pieces approximately 5-cm long and scattered on the soil. Irrigation (AWD) was started on day 7 after the second cutting. The container locations were randomized with four replications in each, with and without fertilizer (32 pots in total). No fertilizer was applied for the ratoons.

\section{Measurements}

We counted the number of panicles and weighed the seeds of whole pots. The maturity of seeds were measured for composite samples of replications by specific gravity (1.06) method. We counted the number of living leaves (being alive was defined as more than half of the leaf being green) at harvesting and the number of ratoons on day 45 after harvesting.

\section{Analysis}

We plotted the relationship between the delay of harvesting and the number of ratoons. We showed statistical significance with a 95\% confidence interval in the graph. We used Microsoft Excel 2016 formulas (average, stdev.s, and confidence) for statistical analysis.

\section{Results}

Growth of the main crop

The rice yields, maturity, and number of panicles were 0.66 $( \pm 0.04) \mathrm{kg} \mathrm{m}^{-2}, 77.4( \pm 3.1) \%$, and $67.5( \pm 3.3) \mathrm{m}^{-2}$ respectively. Not using fertilizer decreased those properties, but a significant difference was found in the number of panicles $(t=0.047)$ only.

\section{Effect of fertilizer}

The application of fertilizer did not reverse the number of ratoons. There was a greater number of ratoons with fertilizer than without fertilizer; the response to delayed harvesting showed the same tendency (Figure 1a). 


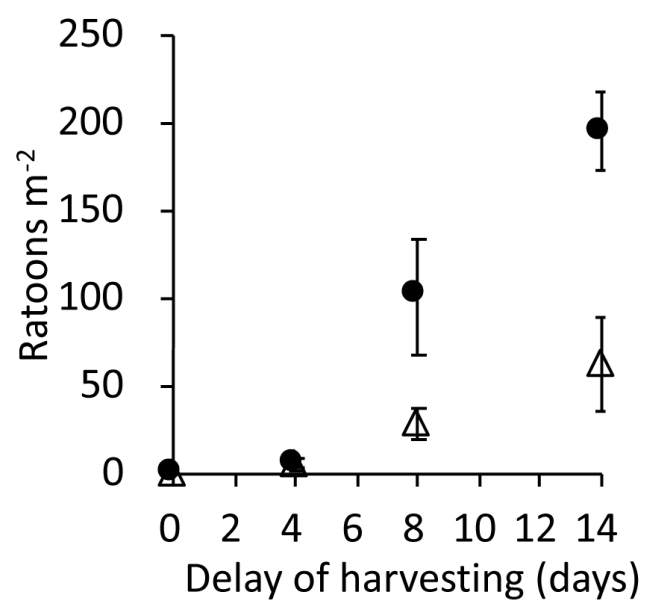

\section{a) Ratoons}

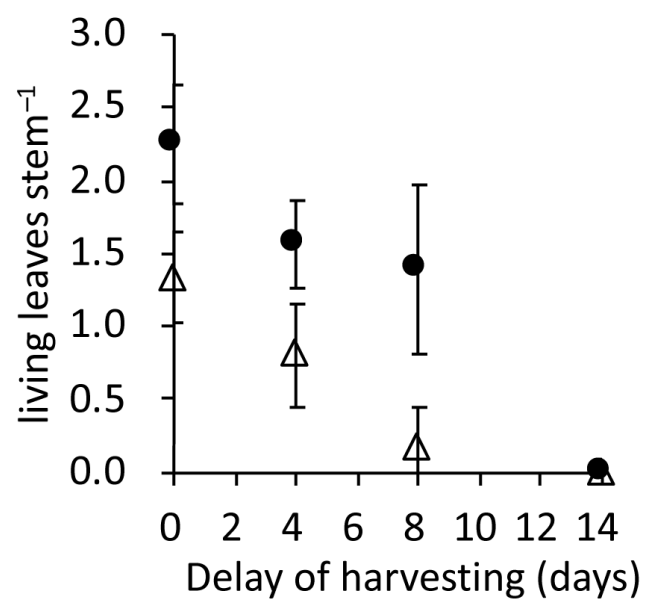

b) Living leaves

Figure 1. Effect of fertilizer and delayed harvesting on cutting twice. $\bullet$ : fertilized, $\Delta$ : unfertilized. Bars represent $95 \%$ CI $(n=4)$. Rice was harvested on the day when $75 \%$ of the seeds on the main stem turned yellow (the standard SALIBU method; days 0 ), and after on days 4, 8, and 14. Rice was harvested at $25 \mathrm{~cm}$ aboveground first, then cut again at approximately 5-cm aboveground on day 7 after each harvesting.

\section{Effect of delayed harvesting}

The number of ratoons increased significantly with increasing delays in harvesting (Figure 1a). In particular, by day 4, there were almost no ratoons. Conversely, living leaves decreased continuously with delayed harvesting (Figure 1b). Finally, by day 14 , there were no living leaves.

\section{Discussion and conclusion}

Oda et al. (2019) show cutting twice can have a large effect on the number of ratoons; however, the effect can be reversed by different management conditions, such as adding fertilizer, delaying harvesting, or changing the type of water management used. We performed a pot experiment to investigate the effects that the level of fertilizer and the delay in harvesting time had on the number of ratoons.

Our results showed that the application of fertilizer does not reverse the effect of cutting twice on the number of ratoons. However, the timing of harvesting can reverse the effect of cutting twice on the number of ratoons. The number of ratoons continuously increased until the rice plants lost all of their living leaves. However, the second cutting conducted on the rice plant harvesting on days 0 resulted in no ratoons. By contrast, the single cutting normally gets ratoons. This means that cutting twice reduces the number of ratoons. Previous work also shows that cutting twice reduces the number of ratoons (Shiraki et al., 2020).

Harvesting earlier than normal (at the physiological maturing stage) is emphasized in the SALIBU technology package; however, our results showed that the second cutting is not advantageous when harvesting at the recommended timing. This is a significant finding for ratoon rice cultivation. The practice of cutting twice originated the custom of conventional harvesting of which cutting height is high. That should be distinguished from using lower nodes of stubble. In other words, twice cutting is recognized as an essential practice in SALIBU (Fitri et al., 2019; Yamaoka et al., 2017) but twice cutting is unnecessary when we can cut rice plant stems near the soil surface at harvesting. The use of a second cutting can have a large effect on the number of ratoons, so further studies should be conducted.

\section{Data availability}

Underlying data

Figshare: Salibu Effect 2. https://doi.org/10.6084/ m9.figshare.13142720.v2 (Oda et al., 2020)

This project contains the following underlying data:

- $\quad$ SALIBU2.xlsx (Ratoon and living leaves data)

Data are available under the terms of the Creative Commons Zero "No rights reserved" data waiver (CC0 1.0 Public domain dedication).

\section{Acknowledgements}

This work was conducted as a joint research project of JIRCAS and CTU. 
Cohen J: A power primer. Psychol Bull. 1992; 112(1): 155-159.

PubMed Abstract | Publisher Full Text

Fitri R, Erdiman, Kusnadi N, et al.: SALIBU technology in Indonesia: an alternative for efficient use of agricultural resources to achieve sustainable food security. Paddy and Water Environment. 2019; 17: 403-410. Publisher Full Text

Oda M, Nguyen HC, Huynh VT: Evaluation of cropping method for perennial ratoon rice: Adaptation of SALIBU to triple-cropping in Vietnam [version 3; peer review: 3 approved, 1 approved with reservations]. F1000Res. 2019; 8: 1825.

PubMed Abstract | Publisher Full Text | Free Full Text

Oda M, Thao Nguyen T, Nguyen HC: Salibu Effect 2. figshare. Dataset. 2020 http://www.doi.org/10.6084/m9.figshare.13142720.v2

Sacks E): Perennial rice: challenges and opportunities. In: Batello, C. ed.
Perennial Crops for food security. FAO, 2013; 16-26.

Reference Source

Safruddin S: Effect of Layout Trimming And Urea Fertilizer Dose On Productivity Of Rice (Oryza sativa L.) Varieties Ciherang System Salibu (Ratoon Modification). AGRICULTURA. 2017; 103(3-4): 21-26.

Reference Source

Shiraki S, Cho TM, Htay KM, et al.: Effects of the Double-Cutting Method for Ratooning Rice in the SALIBU System under Different Soil Moisture Conditions on Grain Yield and Regeneration Rate. Agronomy. 2020; 10(11): 1621 Publisher Full Text

Yamaoka K, Htay KM, Erdiman, et al.: Increasing Water Productivity through Applying Tropical Perennial Rice Cropping System (SALIBU Technology) in CDZ, Myanmar. In: The 23rd ICID Congress: Towards A New Green Revolution 2.0. International Commission on Irrigation and Drainage (ICID). 2017. Reference Source 


\section{Open Peer Review}

\section{Current Peer Review Status:}

\section{Version 1}

Reviewer Report 08 January 2021

https://doi.org/10.5256/f1000research.30144.r76277

(C) 2021 Mayly S. This is an open access peer review report distributed under the terms of the Creative Commons Attribution License, which permits unrestricted use, distribution, and reproduction in any medium, provided the original work is properly cited.

\section{Syarifa Mayly}

Department of Agroecotechnology, Al Washliyah Medan University, Medan, Indonesia

This article addresses the relationship between timing of harvesting (delay harvesting $0,4,8,14$ days) and level of fertilizer (with and without fertilizer) on the number of ratoons from the rice crop that had cutting twice at 7 days after harvesting. The parameters of this research are (1). number of ratoons, (2) living leaves, (3) yield, (4) maturity, (6) panicle. Parameter (1) was measured 45 days after harvesting (after twice cutting practices). Parameters (2-6) were measured at harvesting main crop (before twice cutting practices).

There are a number of issues/statements that need to be clarified, however. Below are more specific comments by section:

\section{Abstract:}

The abstract had contained information about general topics of study, previous study, problem of research addresses, results and conclusions. But the objective of study and analytical methods were not seen clearly. The statement that "the effect changed from positive to negative with changes in the management conditions used to cultivate rice" must be described more specifically and with enough data to justify the statement.

The statement that "By contrast, the single cutting results in ratoons", how to justify this statement when there was no single cutting in this research and all of rice get twice cutting.

And which data in this study can show whether or not there was a reverse effect of twice cutting on number of ratoons from the delay harvesting and level of fertilizer treatment?

\section{Introduction:}

The introduction had contained information about salibu method; gap of previous study that is still unclear. But it needs more information about early planting and the factors which influenced the formation of ratoon like variety, etc. Why did you choose harvesting time at $75 \%$, the seeds on the main stems turned yellow (Physiological maturity), why you do not choose $80 \%$ which is also used in some studies of ratoon rice? 
The statement "The results showed that ...", should be written in the results section.

\section{Methods:}

Need more information about harvesting time at 75\%; obtained on how many days after sowing? And regarding the statement "SALIBU practices are not used in this experiment", it would be clearer to write down which of the 10 additional activities from the Salibu System were not carried out.

\section{Treatments:}

The step of treatments was clear, but needs more information about the details of irrigation (AWD) at ratoon crop. Why don't you use the same variety from the previous study that still have many that can be clarified?

\section{Measurements and Analysis:}

This is clear.

\section{Results:}

- Effect of fertilizer:

Which data can be supported to justify your statement (The application of fertilizer did not reverse the number of ratoons)?

The title of Figure 1 was considered for change which the living leaves were measured before cutting twice practices. Caption 1 needs to add more information about measured time from number of ratoons and living leaves.

\section{Discussion and Conclusion:}

Data showing the reverse effect of twice cutting by timing of harvesting and level of fertilizer are not seen in the results section, so how to justify the statement there was a reverse effect of twice cutting by timing of harvesting?

The statement "The number of ratoons continuously increased until the rice plants lost all of their living leaves" showed that the growth of ratoons and living leaves occurs simultaneously, but actually living leaves was for main crop not ratoon crop. The large number of ratoons in delay harvesting was most likely because there were sufficient food reserves from stem for the growth of ratoons. Some literature suggests that the ratooning performances was affected by varieties, water and fertilizer management, and number of nodes.

Conclusions of this study are not written clearly.

\section{Data Availability:}

Analysis is clear (Mean, STDEV, CI and t test).

Why was only the maturity parameter data not displayed in replication form like other parameters' data? 


\section{Acknowledgement and References:}

This is clear.

Is the work clearly and accurately presented and does it cite the current literature?

Yes

Is the study design appropriate and is the work technically sound?

Yes

Are sufficient details of methods and analysis provided to allow replication by others? Yes

If applicable, is the statistical analysis and its interpretation appropriate?

Partly

Are all the source data underlying the results available to ensure full reproducibility? Partly

Are the conclusions drawn adequately supported by the results?

Partly

Competing Interests: No competing interests were disclosed.

Reviewer Expertise: Value added product (biochar), waste management, drought stress, climate change, tropical agroecosystem, nutrient management

I confirm that I have read this submission and believe that I have an appropriate level of expertise to confirm that it is of an acceptable scientific standard.

Author Response 29 Jan 2021

Masato Oda, Japan International Research center for Agricultural Sciences, Tsukuba, Japan

Thank you very much for your valuable comments. We sincerely appreciate it.

Please check the manuscript as we have revised it as follows.

1. Abstract:

"the effect changed from positive to negative with changes in the management conditions used to cultivate rice" must be described more specifically and with enough data to justify the statement.

- We revised.

How to justify this statement when there was no single cutting in this research and all of rice get twice cutting.

- We explained using literature. 
Which data in this study can show whether or not there was a reverse effect of twice cutting on number of ratoons from the delay harvesting and level of fertilizer treatment?

- We explained.

\section{Introduction:}

The gap of previous study that is still unclear.

- We explained using existing studies.

It needs more information about early planting.

- not "early planting" that is conventional in the Mekong delta. We explained it in the "Methods"

The factors which influenced the formation of ratoon like variety, etc.

- We explained using existing studies. As for variety, we think that it is a future study so we just mentioned it in the "Discussion and conclusion".

Why did you choose harvesting time at $75 \%$, the seeds on the main stems turned yellow (Physiological maturity), why you do not choose $80 \%$ which is also used in some studies of ratoon rice?

- That is the conventional of the Mekong Delta triple rice cropping and of the recommendation of SALIBU practices. We described that in the "Methods".

The statement "The results showed that ...", should be written in the results section.

- Deleted.

3. Methods:

More information about harvesting time at $75 \%$; obtained on how many days after sowing? - On day 91, 95, 99, and 105. We added.

"SALIBU practices are not used in this experiment", it would be clearer to write down which of the 10 additional activities from the SALIBU System were not carried out.

- We added the explanation.

4. Treatments:

More information about the details of irrigation (AWD) at ratoon crop.

- We added.

Why don't you use the same variety from the previous study that still has many that can be clarified?

- Jasmine rice is photoperiod sensitive so it can use for getting ratoons but not practical.

6. Results:

Effect of fertilizer: Which data can be supported to justify your statement (The application of fertilizer did not reverse the number of ratoons)?

- We explained in the "Discussion and conclusion".

The title of Figure 1 was considered for change which the living leaves were measured 
before cutting twice practices.

- We changed to "Rotoons and Living leaves".

Caption 1 needs to add more information about measured time from the number of ratoons and living leaves.

- Thank you. We added.

7. Discussion and Conclusion:

Data showing the reverse effect of twice cutting by timing of harvesting and level of fertilizer are not seen in the results section, so how to justify the statement there was a reverse effect of twice cutting by timing of harvesting?

- We explained it using existing studies. The previous study provides the data.

The statement "The number of ratoons continuously increased until the rice plants lost all of their living leaves" showed that the growth of ratoons and living leaves occurs simultaneously, but actually living leaves was for main crop not ratoon crop. The large number of ratoons in delay harvesting was most likely because there were sufficient food reserves from stem for the growth of ratoons. Some literature suggests that the ratooning performances was affected by varieties, water and fertilizer management, and number of nodes.

- The best harvesting time for good ratooning is when the culms were still greenish because the growth of ratoon tillers depends on the carbohydrate reserves of the stubble (Fukui, 1988). We revised the explanation.

Conclusions of this study are not written clearly.

- We revised.

Competing Interests: No competing interests were disclosed. 
The benefits of publishing with F1000Research:

- Your article is published within days, with no editorial bias

- You can publish traditional articles, null/negative results, case reports, data notes and more

- The peer review process is transparent and collaborative

- Your article is indexed in PubMed after passing peer review

- Dedicated customer support at every stage

For pre-submission enquiries, contact research@f1000.com 